\title{
Perspectiva histórica DE LA METÁFORA DEL CONCEPTO JURÍDICO DE PERSONA. ETIMOLOGÍA E IDEAS EN LA ANTIGÜEDAD
}

\author{
Historical Perspective of the \\ Metaphor of the Legal Concept \\ of PERson. Etymology and IdEAs
}

IN ANTIQUity

Perspectiva histórica da metáfora DO CONCEITO JURÍDICO DE PESSOA. Etimologia e ideias na Antiguidade

orcid.org/0000-0001-7703-6341. Consejo Nacional de Investigaciones Científicas y Técnicas (Conicet), Argentina. helgalell@conicet.gov.ar

RECIBIDO: 06/05/2019. ENVÍO A PARES: 28/05/2019 APROBADO POR PARES: O6/06/2019. ACEPTADO: 18/06/2019

DOI: $10.5294 / D I K A .2019 .28 .2 .4$ 


\section{RESUMEN}

Este trabajo aborda la manera como el concepto jurídico de persona se construye sobre una metáfora antigua que lo relaciona con la metáfora teatral, la cual representa un personaje, y las diferentes interpretaciones que sobre esta noción se han dado en la Antigüedad occidental, y a las que otras concepciones filosóficas han llegado en la actualidad. En particular, el objetivo es señalar que el vocablo no es claro y que, si hoy en día se lo vincula con la idea de humanidad y con ciertas exigencias, ello radica en la evolución semántica del término. En tal sentido, aquí se espera efectuar una breve sistematización de ideas que colaboren en la comprensión de los cambios semánticos.

\section{PALABRAS CLAVE}

Persona; semántica jurídica; Antigüedad; metáfora; concepto jurídico; perspectiva histórica; etimología. 


\section{ABSTRACT}

This paper deals with how the legal concept of person is built on an old metaphor related to the theatrical mask - the performance of a role-, and the various interpretations of this notion in Western antiquity and at which other philosophical conceptions have arrived today. Particularly, the objective is to point out that the word is not clear and that, if it is currently linked to the idea of humanity and certain demands, it is due to the semantic evolution of the term. In this regard, a brief systematization of ideas is presented in order to contribute to the understanding of semantic changes.

\section{KEYWORDS}

Person; legal semantics; antiquity; metaphor; legal concept; historical perspective; etymology. 


\section{RESUMO}

Este trabalho aborda a maneira na qual o sujeito jurídico de pessoa é construído sobre uma metáfora antiga que o relaciona com a metáfora teatral, a qual representa uma personagem, e as diferentes interpretações dadas acerca dessa noção na Antiguidade ocidental, e as que outras concepções filosóficas têm dado na atualidade. Em particular, o objetivo é indicar que o vocábulo não é claro e que, se hoje em dia é vinculado com a ideia de humanidade e com certas exigências, isso radica na evolução semântica do termo. Nesse sentido, neste texto, espera-se realizar uma sistematização de ideias que colaborem na compreensão das mudanças semânticas.

\section{PALAVRAS-CHAVE}

Pessoa; semântica jurídica; Antiguidade; metáfora; conceito jurídico; perspectiva histórica; etimologia. 
SUMARIO: INTRODUCCIÓN. 1. ETIMOLOGÍA DEL TÉRMINO. 1.1 EL ORIGEN ETRUSCO. 1.2. LA MÁSCARA GRIEGA. 1.3. LA MÁSCARA ROMANA. 2. LA CONCEPCIÓN DEL DERECHO EN LA ANTIGÜEDAD GRECO-ROMANA. 2.1. El ESTOICISMO. 2.2. EL CRISTIANISMO. 3. LA ANTIGÜEdad tardía. 3.1. El edicto de milán. 3.2. El Concilio de nicea. 3.3. SAn agustín. 4. Hechos políticos de RELEVANCia que CIERRAN LA ETAPA. 5. Consideraciones FINALES. BIBLIOGRAFÍA.

\section{INTRODUCCIÓN}

El concepto jurídico de persona es uno de los más relevantes en el marco de la teoría general del derecho y de la práctica jurídica. Mientras que, por un lado, es común la definición que remarca que este es un centro de imputación normativa o, en otras palabras, un ente susceptible de adquirir derechos y contraer obligaciones, por el otro, también suele ser caracterizado por su dignidad, inviolabilidad y, en algunas ocasiones, por su autonomía. Estas dos caracterizaciones no siempre son compatibles; en parte, ello se debe a que la versión más extrema del positivismo puede adherir a la primera definición, pero no podría reconocer los atributos de la segunda como necesarios en razón de su caracter moral (en todo caso, podrán ser contingentes). Viceversa, las posiciones jusnaturalistas no podrian aceptar una definición netamente juspositivista por cuanto podría llegar a desconocer o contrariar contenidos propios del derecho natural. A ello hay que agregar que la incompatibilidad no siempre se da. La definición de la persona como ente susceptible de adquirir derechos y contraer obligaciones es tan amplia como ambigua y, por ello, puede vincularse a más de un significado. Así, considerar que la persona tiene dignidad, inviolabilidad y autonomía implica un ente susceptible de adquirir derechos y obligaciones, pero determinado, entonces, por su propio carácter sustantivo. A su vez, entre estas dos posiciones existe una amplia variedad de concepciones con visiones intermedias.

Ahora bien, lo que interesa en este trabajo es comenzar a dilucidar la compleja semántica del concepto jurídico de persona. Ello, por cuanto si al día de hoy es posible observar esta pluralidad de significados, se debe a la apertura que brinda la metáfora sobre la que esta noción se construye. Las figuras retóricas son dinámicas e interpretadas de diferentes maneras según su contexto. ¿Cómo llega a vincularse la máscara teatral con el sujeto de derechos y obligaciones y con el ser humano? Un estudio histórico debería colaborar con la respuesta. Este trabajo intenta iniciar dicha tarea y se concentra solo en la Antigüedad occidental. Cabe aclarar, aunque resulte una obviedad, que este recorte es tan solo una parte de la historia y, por tanto, no puede absolutizarse. Por un lado, existen otros relatos societales sobre la sujetividad y la idea de persona en el derecho. Por el otro, aquí se aborda solo un periodo histórico y, por ende, debe el lector tener en cuenta que aún quedan muchos siglos por analizar.

Finalmente, debo señalar que aquí no se encontrarán contenidos novedosos, pero

314 sí, al menos, sistematizados. Existe una general tendencia a resaltar el vínculo entre el concepto de persona, los estatus romanos y la máscara teatral, pero con olvido del contexto. Asimismo, esta remisión explica la metáfora en el campo del 
derecho sin dar cuenta de por qué la idea de persona llega a significar al ser humano y por qué en el campo jurídico ello acaba por tener un relevante efecto: exigir derechos humanos, trato digno y a la altura de un ser inviolable. En ese marco, es necesario recorrer la historia más allá del hito metafórico y observar cómo, por ejemplo, una concepción religiosa y un evento con fundamento político introdujeron la confusión semántica.

\section{ETIMOLOGÍA DEL TÉRMINO}

Señala Corominas que el término "persona", como cultismo, fue utilizado en todas las épocas de la lengua castellana, pero fue popularizado a finales del siglo XI y principios del XII. Desde allí, ha cobrado la acepción impersonal de "uno, la gente". ${ }^{1}$

Si bien la etimología del término "persona" no es clara, se suele señalar que esta tiene estrecha relación con la máscara utilizada en los teatros romanos (personare). A su vez, esta tenía su correlato en los escenarios de la Antigua Grecia (prósopon). Finalmente, algunos autores mencionan la posibilidad de que los términos latino y griego se remitan a phersu, de origen etrusco. Me detendré brevemente en estos tres supuestos, aunque también es relevante destacar que al contexto teatral se llega a partir de los rituales fúnebres, algo que queda más claro con el término tirreno, como se verá a continuación. En tal sentido, Ribas destaca que

... toda indagación sobre el concepto de persona debe iniciarse en este punto de partida: el de las creencias y rituales relacionados con el mundo de ultratumba. Comenzar la historia a la altura de la máscara teatral supone dejar de lado una parte sustancial, tal vez la más determinante y significativa: la de los orígenes, hasta donde nos es dado conocerlos. Por otra parte, la máscara teatral presupone un teatro preliteriario: ámbito ritual en el que la danza, la música y las palabras expresan una invocación religiosa particularmente vinculada con dioses en los que el aspecto subterráneo y mortuorio tiene un peso esencial: el Dionisio / Baco griego y el Liber Pater romano ambos con una multiplicidad de epítetos que no deben hacernos olvidar su unicidad, están en el origen del teatro greco-latino, pero también protagonizan gran parte del ritual concebido para la relación con el mundo de los difuntos. ${ }^{2}$

En estos rituales teatrales "preliterarios", la máscara representaba al dios invocado o al difunto. La representación no se tomaba como una mera ficción, sino que se la asumía con cierto carácter realista. La máscara volvía a hacer presente algo que ya no estaba, aunque había estado, es decir, representaba. La máscara, en aquel escenario previo a los teatros literarios, se enmarca en el culto a los difuntos. ${ }^{3}$

1 Joan Corominas, "Persona”, Diccionario crítico etimológico castellano e hispánico, ME-RE. Con la colaboración de José A. Pascual, Madrid, Gredos, 1981.

2 José María Ribas Alba, Persona: desde el derecho romano a la teología cristiana, 2 ed., Granada, Comares, 2012, p. 106.

3 Javier, PARICIO, "Persona: un retorno a los origenes". En Matilde Cuena Casas, Luis Antonio Anguita Villanueva y Jorge Ortega Doménech (coords.), Estudios de derecho civil en Homenaje al profesor Joaquín José Rams Albesa, Madrid, Dykinson, 2015, p. 281. 
Ya sea en los rituales funerarios o en los teatrales, en lo que interesa a este trabajo, la máscara muestra la representación de algo, es decir, la personificación de algo que, de no estar este elemento, estaría también ausente. No es solo el ejercicio del rol, sino, ante todo, volver a hacer presente.

\subsection{El origen etrusco ${ }^{4}$}

En la provincia de Tarquinia, en Italia, se ubica un sitio arqueológico de gran valor histórico: la necrópolis de Monterozzi, que data de la segunda mitad del siglo VI a.C. Entre los puntos de mayor interés puede encontrarse la tumba de los Augures que cuenta con diversos frescos en sus paredes. Precisamente, alli es en donde en dos pinturas aparece un personaje denominado Phersu. En la pared derecha se aprecia un hombre que utiliza una máscara rojiza con barba y gorro en punta. Este sostiene una cuerda que enreda a otro sujeto. Este último tiene la cabeza cubierta, una maza en la mano y cuenta con algunas heridas producidas por el ataque de un perro que, a su vez, lo muerde en una pierna. Se ha interpretado que esta escena retrataría la ejecución de una condena a muerte, aunque también podría ser una competencia. En la pared izquierda, el personaje vuelve a aparecer. Por supuesto, porta la misma máscara, aunque ahora tiene una vestimenta diferente. Mientras en el primer mural esta era de color azul y blanco, ahora es de color rojo. Phersu pareciera estar corriendo y mirando hacia atrás. En el mismo sitio arqueológico, la figura reaparece en otros murales, aunque en peor estado de conservación. En la tumba de las Olimpiadas, también es un ejecutor. En la tumba de Pulcinella, se encontraría corriendo.

Si bien no existe mucha claridad respecto de quién era Phersu en la cultura etrusca, se cree que podria haber sido un dios del inframundo o, en una versión que cuenta con mayor consenso, un ejecutor cuya máscara simbolizaba los espíritus de la muerte y su reaparición/representación. Al menos sí se puede afirmar que relaciona la máscara con una escena y, quizás, con la representación de un rol.

El pueblo etrusco estuvo presente desde el siglo VIII a. C. en la región de la hoy Toscana italiana (posteriormente, también se expandieron hacia otras zonas, principalmente hacia el norte de Italia) y en permanente contacto con las culturas tanto romana como griega. Aproximadamente, hacia el año 40 a. C., las ciudades etruscas se convirtieron en parte de la República romana.

4 En este apartado, respecto de la iconografía de Phersu, se han seguido las siguientes obras: David LARMour, The Arena of Satire: Jouvenal's Search for Rome, Norman, University of Oklahoma Press, 2016, pp. 207-208; Sthephan STEINGRÄBER, Abundance of life. Estruscan Wall painting, Los Ángeles, Getty Publications, 2006, pp. 67 y 93-100; Donald KyLE, Sport and Spectacle in the Ancient World, New Jersey, John Wiley and Sons, 2014, p. 258; Simon StoddarT, "Phersu". Historical Dictionary of the Etruscans. Darmstadt, Scarecrow Press, 2009, p. 147. Sobre la cultura etrusca, ver Christopher Sмiтн, The Etruscans. A Very Short Introduction, Oxford, Oxford University Press, 2014; Steven Hause y William MaLtBy, Western Civiliation: A History of European Society from Antiquity to Renaissance. West/Wadsworth, 1998. 


\subsection{La máscara griega}

El término prósopon ( tros griegos y se lo asocia, también, con el individuo que ella representa, esto es, se unifica el sentido del actor y su rol como personaje. ${ }^{5}$ Tardiamente, también habría llegado a designar al individuo detrás de ella. El término proviene de prós-

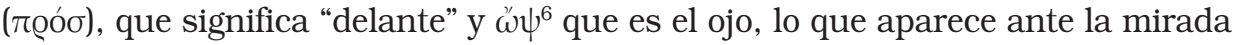
de otro o el rostro.

En cuanto a la máscara en sí, es decir, como elemento material, habría sido utilizada, en primer lugar, en rituales dionisiacos y servía para dar anonimato a los participantes. En el contexto del teatro, originariamente permitía interpretar un personaje, pero, en sus primeras versiones, la confección y el material no habrían permitido amplificar la voz. Fue así cuando se incorporó una lámina de metal en el orificio bucal. En cuanto a la expresividad, Néndoncelle menciona que era poca ya que existían máscaras para los dioses y héroes; el resto se clasificaba según el sexo, la edad y la emoción por representar. ${ }^{7}$

Chantraine explica que prósopon varió ligeramente su sentido. Mientras que Homero (VIII a. C.) lo utiliza con el significado de rostro, en algunos trágicos significa la expresión del rostro; Demóstenes (IV a. C.) y los cómicos áticos lo asocian a la máscara y Filodemo el filósofo (I a. C.) lo menciona como personaje de una obra de teatro. ${ }^{8}$ Para Scholssman, existiría un único pasaje (XXVII, 7, 4) en las Historias de Polibio (siglo II a. C.) en el cual la única traducción posible es aquella de individuo. ${ }^{9}$

En la lengua griega de la Antigüedad, otros términos designaban al hombre en oposición a los dioses y los animales, ya fuera para nombrar la naturaleza humana

$5 \quad$ Henry George Liddell y Robert ScotT, A Greek-English Lexicon. Revisado por Henry Stuart Jones con la colaboración de Roderick McKenzie, Oxford, Clarendon Press, 1940 (publicado por Perseus Project).

6 Las entradas provienen de LidDell y ScotT, An Intermediate Greek-English Lexicon, op. cit.

7 Maurice NÉndoncelle, "Prósopon et persona dans l'antiquité classique. Essai de bilan lingüistique". Revue des Sciences Religieuses, t. 22, 3-4 (1948), p. 281.

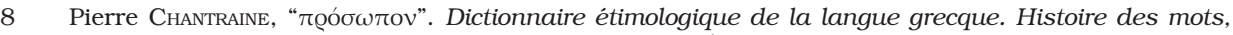
t. III ( $\Lambda$-П), Paris, Klincksieck, 1974, p. 942; Miguel Ángel Belmonte, "Los antecedentes remotos:

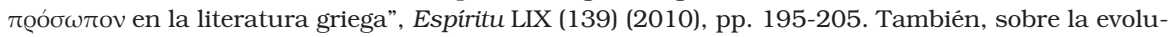
ción del concepto de prósopon en la lengua griega (que abarca desde el sentido de rostro hasta la persona gramatical), ver François LÉTOUBLon, "La personne et ses masques: remarques sur le développement de la notion de personne et sur son étymologie dans l'histoire de la langue grécque”, Faits de langues 3 (1994), pp. 7-14.

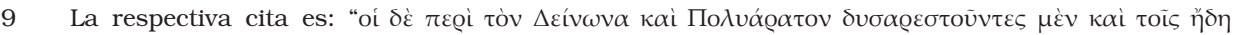

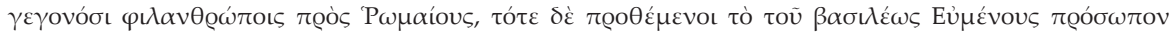

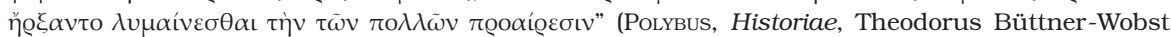
after L. Dindorf, Leipzig, Teubner, 1893. Publicada on-line por Perseus Project). Ver Siegmund Schlossmann, Persona und Prósopon im Recht und im christlichen Dogma, Wissenschaftliche Buchgesellschaft, 1968, p. 84. Cabe destacar que Néndoncelle y Belmonte citan otro pasaje, por lo que es posible que su remisión no sea adecuada (ver Maurice NÉndoncelle, "Prósopon et persona dans l'antiquité classique", op. cit., pp. 277-299); Miguel Ángel Belmonte, "Los antecedentes remotos:

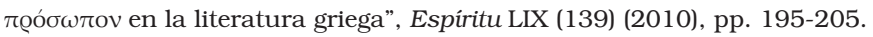


en general ( $\alpha v \theta \varrho \omega \pi \circ \varsigma)$ o al varón ( $\alpha \dot{v} \emptyset$ ). Cuando los griegos comenzaron a explorar la naturaleza humana como tema de la literatura, utilizaron otros términos

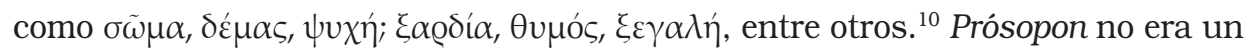
sinónimo de ellos.

A partir de allí, diversos autores han sostenido que solo muy tardiamente el vocablo griego pudo dar lugar a la idea de persona como ser humano y que, precisamente, este sentido habría sido inspirado por la influencia del latín que encontraba dificultades para traducir la ambigüedad de prósopon. ${ }^{11}$

Si bien, entonces, los griegos no pensaron en la asociación entre individuo y prósopon, será en el contexto de las disputas teológicas del Concilio de Nicea cuando este término cobre una trascendencia fundamental en el cambio semántico de "persona".

\subsection{La máscara romana}

El término "persona" proviene del latín persōna ${ }^{12}$ y significa, tal como es conocido, la máscara del actor o el personaje teatral. Proviene de per- y sonare, es decir, era un instrumento para amplificar la voz de la persona que se encontraba en escena. El respectivo instrumento, en el orificio bucal, tenía una membrana que permitía aumentar el sonido. ${ }^{13}$ La metáfora, en este sentido, muestra que es a través del papel que se interpreta, que se habla, que se presenta el sujeto. Como puede notarse, aquí existe una ligera diferencia con la máscara griega que hace hincapié en la mirada, en la cobertura del rostro, en aquello que se ve o se presenta. A pesar de ello, ambas refieren a una diferenciación entre actor y personaje. De alli es que esta denominación también se extendió al lugar que un individuo ocupa en las relaciones sociales. ${ }^{14}$

En la antigua Roma, no todo ser humano era persona: en primer lugar, quien nacía debía tener forma de ser humano y viabilidad de vida. Además de ello, la persona se definía por su relación con la ciudad, la familia y la libertad, esto es, por los estatus civil, familiar y de libertad -valga la redundancia-. Así, la persona, en su máxima expresión, era quien revestía los estatus de un hombre libre, ciudadano romano y padre de familia. Asimismo, existian grados de capacidad en el ejercicio de derechos y de adquisición de obligaciones según el respectivo estatus (por

NÉndoncelLe, "Prósopon et persona dans l'antiquité classique”, op. cit., pp. 277-299.

Ver Alfred ERnout y Antoine Meillet, Dictionnaire étymologique de la langue latine. Histoire des mots, $4^{\circ}$ ed., Paris, Klincksieck, 2001, p. 500 .

COROMINAS, "Persona", op. cit.

José Ignacio Morales, Derecho Romano, 3 ed., México, Trillas, 1989, p. 152.

14 Cfr. Eugène Petrt, Tratado elemental de Derecho Romano, 23ํe․, México, Porrúa, trad. de la novena edición francesa y aumentado por José Ferrández González, 2015, p. 75; Luis Rodolfo ARgüEllo, Manual de derecho romano. Historia e instituciones, Buenos Aires, Astrea, pp. 70-71; Faustino Gutiérrez-Alviz y Armarlo, "Persona", Diccionario de Derecho Romano, 3 o ed., Madrid, Reus, 1982, p. 528. 
ejemplo, un hijo era padre de familia, pero sí tenía un rol dentro de ella). La conjunción de estos tres estatus, a su vez, constituía la calidad de caput (cabeza ${ }^{15}$ ). ${ }^{16}$

Más allá del plano metafórico, en el vocabulario jurídico romano existe una distinción entre caput, o sea, la cabeza, y persona, es decir, entre el individuo y la persona. En efecto, la máscara es la forma exterior por la que se reconoce la función, la personalidad, el rol que corresponde en el marco de una escena al actor en cuya cabeza se coloca aquella máscara. Así, la cabeza es interior y la máscara es exterior: la cabeza sostiene la personalidad. Por extrapolación a la vida jurídica, la cabeza no es más que la individualidad humana natural considerada aisladamente. En cambio, toda relación de los hombres con otros se refiere, no a la individualidad humana natural, sino a la persona. Consecuentemente, la persona es individualidad humana en comunicación o relación intersubjetiva o social con otros. ${ }^{17}$ Agrega Betancour que mientras la individualidad humana natural es única (caput), su personalidad puede variar según la distinta relación social en que se integra (persona). Por tanto, la personalidad tiene un carácter esencialmente relativo; está en función de las relaciones intersubjetivas o sociales. ${ }^{18}$

Otra noción vinculada con el concepto de persona es la de homo. Por esta se entendía la mera unidad psicofísica, es decir, un ente racional con cuerpo humano. En contraste con ello, la persona era el mismo hombre, pero considerado según sus circunstancias sociales, familiares y civiles. ${ }^{19}$

A partir de la metáfora de la máscara, en el ámbito jurídico, el concepto de persona ha sido identificado con un centro de imputación normativa, esto es, con un sujeto de derechos y obligaciones en el marco de relaciones externas y de alteridad. Esto es comprensible ya que implica una escena determinada en el marco de relaciones jurídicas, el ejercicio de un rol, la utilización de una máscara en particular (por ejemplo, ser un locador en un contrato de locación, un hijo en una relación de filiación, un jubilado dentro de un sistema de seguridad social, un homicida a la luz de un código penal, un candidato a la luz del sistema electoral, etc.) y la percepción de otros individuos que reconocen el respectivo papel ejercido. ${ }^{20} \mathrm{~A}$ pesar de lo dicho, esta definición y su conexión etimológica con la tecnologia corporal deja vigente la duda respecto de la relación que existe entre el concepto jurídico de persona y ciertas notas que se le atribuyen en el marco de la teoría jurídica y de las normativas: la dignidad, la inviolabilidad y la autonomía. La metáfora por sí misma solo explica la percepción externa de las acciones de un sujeto, el campo jurídico

15 Cabe destacar que era posible modificar estos estatus. Una posibilidad era la capitis deminutio (máxima, media o mínima, conforme al o a los estatus perdidos).

16 Morales, Derecho romano, op. cit., pp. 153-191.

17 Fernando Betancourt, Derecho romano clásico, 3 ed., Sevilla, Universidad de Sevilla, 2007, pp. 51-52.

18 Idem.

19 Cfr. Alfredo Di Pietro y Ángel Enrique Lapieza Eldi, Manual de derecho romano, 4 ed., Buenos Aires, Ediciones Buenos Aires, 1985, p. 70.

20 Esto en tanto una de las características clave en la distinción entre derecho y moral es la intersubjetividad y exterioridad de las conductas. 
como escena y la interpretación de un rol por parte de un individuo. Esta idea, hasta aquí, podría ser perfectamente congruente con un positivismo extremo que aceptara como contenido jurídico un trato cruel e inhumano. ¿Cómo se llega desde el recurso retórico a una sustancia humana con atributos?

\section{LA CONCEPCIÓN DEL DERECHO EN LA ANTIGÜEDAD GRECO-ROMANA}

Además de lo mencionado en el apartado anterior, cabe destacar algunas cuestiones respecto de la concepción jurídica en la Antigüedad greco-romana. Si bien no existía una teoría sobre el derecho propiamente dicha, sí existían algunas nociones. El jus era pensado en relación con la justicia y, por tanto, con un parámetro distributivo que mantuviera cierto grado de igualdad entre las partes intervinientes. Lo justo en el pensamiento de los griegos y romanos es el equilibrio regulativo inmanente en la naturaleza de las cosas, es la justa distribución de los bienes siguiendo un orden social espontáneo y, por ende, natural. ${ }^{21}$ Por ejemplo, Aristóteles (384-322 a. C.) clasifica la justicia particular en distributiva (cuando el Estado otorga privilegios y honores a los particulares según sus méritos) y conmutativa (entre los particulares, ya sea de origen contractual, cuando la igualdad es establecida por las partes al equiparar las prestaciones, o judicial, para restaurar la igualdad violada ante la comisión de un delito o ante el incumplimiento contractual). La concepción del derecho en Aristóteles, indisociable de la caracterización de la justicia particular, se determina, sobre todo, por necesitar de otro sujeto frente al cual se actúa; esto es, por la alteridad. ${ }^{22} \mathrm{El}$ hecho de que una conducta se dé entre dos individuos implica que sea externa o exterior al actor puesto que si la acción nunca excede la mente de un ser, entonces, nunca podrá vincularse con alguien más. ${ }^{23}$ En el caso contrario, es decir, si se tratara de una acción completamente individual, no se estaría en el marco de la justicia particular, sino de la universal, en la búsqueda del actuar virtuoso. ${ }^{24}$ La exterioridad de la conducta cobrará relevancia cuando se trate el cambio de paradigma en el tránsito hacia la Modernidad.

21 Francesco Viola, "El estatuto jurídico de la persona", Derecho y cambio social 40 (XII) (2015), p. 6.

22 Guido FAssò, Historia de la Filosofia del Derecho, t. I, Madrid, Pirámide, trad. José Lorca Navarrete, 1982, pp. 59-71.

23 Viola, op. cit., p. 7, por ejemplo, trae a colación el Libro V de la Ética a Nicómaco que no distingue el deber de restituir una cosa prestada de aquel de restituir una cosa robada (en todo caso, la diferencia radica en la licitud o ilicitud de la causa).

24 Sobre la concepción aristotélica del derecho, ver FAssò, Historia de la Filosofía del Derecho, op. cit., pp. 59-71; Jean-François BAUlaUdÉ, "Instituir el bien. La problemática filosófica de la justicia en la Antigüedad (Platón, Aristóteles, Epicuro)”, en Patrick Wotling (dir.), La justicia, Buenos Aires, Nueva Visión, trad. Viviana Ackerman, 2008, pp. 9-36; Arthur Hilary ARMSTRONG, "Aristóteles (IV). Ética y Política”, Introducción a la filosofia antigua, Buenos Aires, Eudeba, pp. 164-187; Helga LelL, "El derecho como reparto desde la concepción de justicia aristotélica", en María Cecilia Colombani, Guido Fernández Parmo, Juan Manuel Gerardi (comps.), Historia de la filosofia antigua: Actas de las V Jornadas, Mar del Plata, Universidad Nacional de Mar del Plata, pp. 78-87; Helga LeLL, "The Aristotelian conception of law: characterization and way of life according to the Nichomachean Ethics". Ponencia presentada en el XXIII Congreso Mundial de Filosofia, llevado a cabo del 4 al 10 de agosto de 2013 en Atenas, Grecia. 
Por otro lado, también es interesante destacar la concepción jusnaturalista de corte cosmológico predominante en la Antigüedad, sobre todo la griega. Esta implica reconocer que existe un justo por naturaleza y que es externo a los individuos. Estos últimos deben adaptarse al orden natural ya que, de lo contrario, será el mismo cosmos el que restaure el estado de las cosas. Un ejemplo claro de esta idea se puede encontrar en la obra de Sófocles, particularmente en Edipo Rey y en Antígona, escritas, aproximadamente, en el siglo V a.C.

Edipo era hijo biológico de Layo y Yocasta. El oráculo le había dicho al rey Layo que moriria en manos de uno de sus hijos y, por este motivo, se ordenó la muerte de Edipo cuando era niño. No obstante, su ejecutor no pudo completar la tarea y abandonó al bebé. Este fue criado por un matrimonio. Edipo, al ser mayor, consultó al oráculo y este le dijo que mataría a su padre y se casaría con su madre. Por este motivo, dejó su hogar. En el camino tuvo una disputa con un hombre. En la pelea, Edipo mató a su contrincante quien era, sin que él lo supiera, su padre biológico. Al llegar a la ciudad de Tebas se encontró con una esfinge que impedía la circulación y proponía un enigma. Quien lo resolviera se convertiría en rey. El afortunado fue Edipo que, además, desposó a Yocasta ignorando que era su madre. La obra de Sófocles se inicia años más tarde cuando una peste azota a Tebas. Al indagar los motivos de dicho castigo natural, se señala que la muerte del anterior rey, Layo, ha quedado impune. Este hecho desata la furia de los dioses. La falta debe expiarse. Mientras la ciudad no castigara al asesino, sería ella misma castigada por el orden natural. Por este motivo, Edipo emprende una investigación hasta dar con la fatídica respuesta: Layo era su padre biológico y también el hombre al que había asesinado en el cruce de los caminos. Además, se había casado con su madre y sus hijos eran a la vez sus hermanos. Al tratar de huir de su destino, lo había cumplido. Yocasta se suicida y Edipo se arranca los ojos. La impotencia humana ante su destino queda demostrada, además, por el balance entre el orden natural y la voluntad de los hombres. ${ }^{25}$

El mito relata que, tras la muerte de Edipo, ${ }^{26}$ sus dos hijos varones debian turnarse en el trono. Culminado el mandato de Eteocles, este se rehúsa a traspasar el mando a Polínices y este último emprende una guerra contra Tebas. En la batalla mueren ambos hermanos. La obra de Antígona inicia cuando Creonte, tío de ambos y ahora a cargo del gobierno de Tebas, establece que Eteocles sea sepultado con honores mientras que Polinices no debe ser enterrado y su cuerpo queda abandonado a la intemperie, fuera de la ciudad. Antígona (una de las hermanas de ambos) decide desobedecer la norma por no ser acorde con el derecho natural (las leyes no escritas, inmutables, dictadas por los Dioses). Tras ser capturada enterrando a su hermano, tuvo lugar una discusión con Creonte quien acabó por condenarla a muerte. Sería sepultada viva. Tiempo después

25 Ver Sófocles, Edipo Rey, Madrid, Gredos, trad. María Rosa Lida, 2014. Para la versión en griego, ver Sophocles, Oedipus the king. Oedipus at Colonus. Antigone, vol. 1, traducción al inglés por F. Storr. London, New York, William Heinemann; The Macmillan Company, 1912 (publicada por Perseus Project on line).

26 La trilogía incluye una obra más, Edipo en Colono, sobre la cual no nos detendremos aquí. 
Creonte decide dar marcha atrás con la decisión puesto que ha notado su injusticia. No obstante, Antígona había decidido suicidarse para evitar el sufrimiento de una muerte lenta. Hemón, su prometido e hijo de Creonte, al ver muerta a su amada, también se quitó la vida. Al oír estas noticias, la madre de Hemón y esposa de Creonte imita esta conducta. En este trágico relato puede verse cómo la desobediencia del derecho natural, la comisión de un acto injusto provoca una reacción del cosmos que inmediatamente castiga al sujeto actuante; se trata, entonces, de restablecer un orden. ${ }^{27}$

\subsection{El estoicismo}

Si bien la obra de Sófocles es anterior a la escuela filosófica estoica, existen algunos puntos de coincidencia. El estoicismo, como corriente filosófica fundada en el año 301 a.C. por Zenón de Citio, lleva su nombre por sentarse entre las columnas (stoas) en el marco del ágora. Si bien el estoicismo ha tenido una larga duración (se habla de estoicismo, medio y nuevo), además de una influencia constante a lo largo de la historia de las ideas filosóficas (como ser menciona luego, reaparece, por ejemplo, en la concepción cristiana y, particularmente, en Boecio), se puede describir un conjunto minimo de ideas que permiten entender el papel crucial que ha jugado en la semántica del concepto de persona.

Respecto de la concepción ética de los estoicos, estos creen en que el universo está animado por un principio absoluto y universal que es inmanente al mundo. Sostienen, asimismo, que la eudemonía es el ejercicio constante de la virtud, en la propia autosuficiencia que permite al hombre desasirse de los bienes externos. El primer imperativo ético es vivir de acuerdo con la naturaleza, esto es, conforme a la razón, pues lo natural es racional. La felicidad radica en la aceptación del destino, en el combate contra las fuerzas de la pasión que producen intranquilidad. Al resignarse al destino, el hombre se resigna a la justicia puesto que el mundo es en tanto que racional, justo. El mal consiste en lo que es contrario a la voluntad de la razón del mundo, en el vicio, en las pasiones en cuanto destruye y perturba el equilibro. ${ }^{28}$

Los hombres son pequeños cosmos; como fragmentos de la naturaleza que son, tienen parte de ella. El alma racional del hombre es un soplo ígneo que forma parte del soplo ígneo universal, la razón divina o Dios que determina todas las cosas del universo. Por ende, la finalidad del hombre debe consistir en vivir en absoluta conformidad con dicha razón dirigente que es parte de la Razón divina. ${ }^{29}$ El conocimiento intelectual del orden cósmico se convierte en el poder moral de actuar.

27 Sófocles, Antígona, Madrid, Gredos, trad. Asella Alamillo Sánz, 2014. Para la versión en griego, ver Sophocles, Oedipus the king. Oedipus at Colonus. Antigone, vol. 1, traducción al inglés por F. Storr. London, New York, William Heinemann; The Macmillan Company, 1912 (publicada por Perseus Project on line).

28 José Ferrater Mora, "Persona”. Diccionario de filosofia, t III, K-P. Edición actualizada bajo la dirección de Josep-Maria Terricabras, Barcelona, Ariel, 1994, pp. 1120-1124. FAssò, Historia de la Filosofia del Derecho, op. cit., pp. 76-80.

29 Recordemos que los estoicos identifican al fuego como el inicio de todo. 
Esto pone el acento en la conciencia y en el carácter universal del sujeto. ${ }^{30}$ Cicerón (I a.C.), por ejemplo, señala que las relaciones objetivas entre las cosas no dependen del hombre, pero del hombre depende conformarse a ellas. ${ }^{31}$

En cuanto a la temática de este artículo, existe una cita del Enchiridion de Epicteto (I-II d. C.) que es sumamente ilustrativa sobre la concepción de la persona en la Antigüedad y, sobre todo, de la combinación de la concepción estoica de la adaptación del ser humano a la ley natural y de la metáfora de la máscara. Dice:

Sabes que eres el actor de un espectáculo, elegido por el director del teatro, breve si lo desea breve, largo, si lo desea largo; y si él quiere que hagas el mendigo, tienes que hacer bien esta parte; y lo mismo si se trata de un tullido, un principe o un ciudadano particular. Tu tarea consiste en hacer bien la parte que te ha sido asignada; elegirla, sin embargo, corresponde a otro. ${ }^{32}$

\subsection{El cristianismo}

El nacimiento de Cristo marcó una inflexión en la historia, no solo en la forma en que computamos las eras, sino también en la concepción política y moral de las relaciones sociales. El impacto, por supuesto, también se hizo sentir sobre el concepto de persona. El movimiento cristiano y los textos que de él han resultado son innumerables y han sido ampliamente tratados desde lo filosófico y lo religioso. En virtud de la imposibilidad de detenerme en detalle, me concentraré solo en algunos hitos representativos por la influencia posterior en la concepción jurídica de la noción estudiada.

Como se mencionó, la Antigüedad griega y la romana concebian una relación entre el Estado y el individuo. En cambio, con la llegada del cristianismo aparecieron la posibilidad de divergencias entre la religión y la voluntad estatal y la necesidad de poner a Dios por encima de las autoridades positivas.

El impacto político del cristianismo fue profundo por cuanto la interpelación a los individuos dejó de concentrarse en los estatus conferidos por el Estado, para

30 Armstrong, "Filosofias helenísticas (I). Cínicos y estoicos", op. cit., pp. 188-212; Viola, "El estatuto jurídico de la persona", op. cit.,

31 "Est quidem vera lex recta ratio naturae congruens, diffusa in omnes, constans, sempiterna, quae vocet ad officium iubendo, vetando a fraude deterreat; quae tamen neque probos frustra iubet aut vetat nec improbos iubendo aut vetando movet” (Cicerón, De republica, III, 33).

32 Eicteto, Enchiridion, 17. Esta traducción en español figura en Viola, "El estatuto jurídico de la

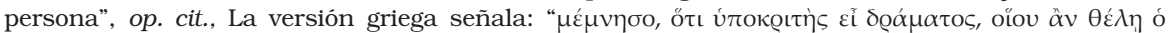

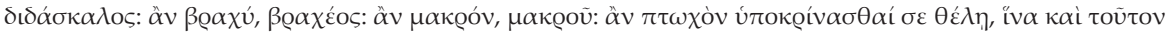

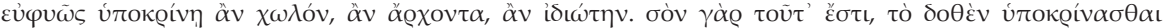

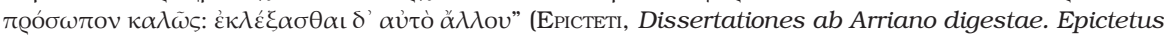
Heinrich Schenkl (ed.), Leipzig. B. G. Teubner, 1916) (publicado por Perseus Project). Asimismo, la traducción al inglés publicada por Perseus Project dice: "Remember that you are an actor in a drama of such sort as the author chooses, - if short, then in a short one; if long, then in a long one. If it be his pleasure that you should enact a poor man, see that you act it well; or a cripple, or a ruler, or a private citizen. For this is your business, to act well the given part; but to choose it, belongs to another" (EPICTETus, The Works of Epictetus: His Discourses, in Four Books, the Enchiridion, and Fragments, New York, Thomas Nelson and Sons, trad. Thomas Wentworth Higginson, 1890). 
interpelar a los hombres por sí mismos y en un pie de igualdad, como hijos de Dios. ${ }^{33}$ La separación de los ámbitos religioso y civil, que se sintetiza en la frase bíblica "Dad al César lo que es del César y a Dios lo que es de Dios" ${ }^{34}$ resquebraja las relaciones sociales como eran conocidas hasta entonces. El hecho de interpelar al hombre como tal y no en el marco de su estatus social o familiar puso la dignidad en el centro de la escena para posibilitar el desarrollo humano como ente espiritual sin necesidad de mediación estatal. Las autoridades politicas y las religiosas se separaron. ${ }^{35}$

Un texto que muestra esta nueva concepción de la humanidad y los lazos entre personas de manera independiente del estado jurídico es la Epístola a Filemón, del apóstol San Pablo (I d. C.). Allí, el apóstol, en ese entonces prisionero, escribe a su interlocutor solicitando que reciba a Onésimo, un esclavo que se había apartado de su amo, el mismo receptor de la misiva. El pedido apunta que Onésimo -el esclavo- ya no debe ser visto por su estatus en la sociedad romana, sino como un hombre nuevo, un cristiano. Por ello, Filemón, líder de la iglesia en Colosas, debía recibirlo como un hermano en Cristo y no castigarlo severamente por su huida, como hubiera correspondido conforme a la legislación positiva. Claramente, en esta pieza bíblica se separa la concepción humana de la persona de aquella estatal a la par que muestra el rol transformador de la sociedad que posee la religión. ${ }^{36}$

\section{LA ANTIGÜEDAD TARDÍA}

Diferentes sucesos políticos y sociales implican una transición desde la Antigüedad clásica hacia el Medioevo. En particular, la crisis acaecida en el marco del Imperio romano que acaba con la asunción de Diocleciano es un hito relevante para marcar el inicio de la Antigüedad tardía.

El gran crecimiento de la religión cristiana era visto como el causante de las rupturas que ocurrian en el Imperio romano y por ello se organizaron fuertes persecuciones a quienes la practicaran. Al comenzar el siglo IV, la estructura del poder romano enfrentaba serios problemas. Tras la abdicación de Diocleciano, los cristianos se habian convertido en una fuerza muy importante que no podía ser erradicada ni ignorada. En el año 311, se decretó el cese de las persecuciones

33 Ariel Álvarez Gardiol, Manual de filosofia del derecho, Buenos Aires, Astrea, 1979; Helga Lell, "Instituciones jurídicas y filosóficas en la Edad Media”, en Lidia Raquel Miranda (ed.), La Edad Media en capitulos. Panorama introductorio a los Estudios Medievales, Santa Rosa, EdUNLPam, 2014, pp. 85-112.

34 Mateo 22,21; Marcos, 12,17; LucAs, 20,25.

35 Ricardo Zorraguín Becú, Historia del derecho argentino, t. I, Buenos Aires, Perrot, 1966; Claude Du PASguier, Introducción a la teoría general del derecho y la filosofia jurídica, Lima, Librería e imprenta Gil, 1944.

36 El tópico de la personería en esta epístola ha sido tratado en Raquel Miranda y Helga LelL, "Derecho divino y derecho positivo en la Epístola a Filemón: una mirada a las esferas de la esclavitud y la hermandad desde la filosofia jurídica existencial", en Maria Cecilia Colombani (coord.), Actas de las Segundas Jornadas de Filosofia Antigua Doctor Francisco Olivieri, Mar del Plata, UNMDP, 2012, y en Raquel Miranda y Helga Lell, "Coexistencia de instituciones de órdenes normativos contrapuestos en la Epístola a Filemón”, Revista classica, Belo Horizonte, Sociedade Brasileira de Estudos Clássicos y Editora Paz e Terra, 2013, pp. 117-129. 
anticristianas. En ese marco, Constantino, uno de los principales sucesores del poder, insatisfecho con la posición obtenida en el reparto de cargos, comprendió la necesidad de contar con el respaldo de los cristianos, no solo como una masa social de apoyo, sino también como un factor de cohesión en un vasto territorio imperial, que cada vez corría más peligros de fracturas internas y de invasiones externas.

\subsection{El Edicto de Milán}

Durante muchos siglos, el cristianismo estuvo proscrito en el Imperio romano y era perseguido, tal como se mencionó. Ejemplo de ello fue la Gran Persecución, del año 303, en la que se removieron de los cargos públicos a cristianos, se confiscaron iglesias, se destruyeron copias de la Biblia, etc. Esta situación comienza a cambiar cuando, en el año 312, Constantino y Licino emprenden una batalla contra Majencio, adverso a los cristianos. En la batalla, Constantino habría mandado a representar en los escudos el monograma cristiano con las letras griegas X (ji) y P (rho) como símbolo protector.

Lo anterior desembocó en que, en el año 313, Constantino y Licinio se reunieran en Milán. Allí se promulgó el conocido Edicto de Milán que permitió la libertad de cultos en el marco del Imperio.

Yo, Constantino Augusto, y yo también, Licinio Augusto, reunidos felizmente en Milán para tratar de todos los problemas que afectan a la seguridad y al bienestar público, hemos creído nuestro deber tratar junto con los restantes asuntos que veíamos merecían nuestra primera atención el respeto de la divinidad, a fin de conceder tanto a los cristianos como a todos los demás, facultad de seguir libremente la religión que cada cual quiera, de tal modo que toda clase de divinidad que habite la morada celeste nos sea propicia a nosotros y a todos los que están bajo nuestra autoridad. Así pues, hemos tomado esta saludable y rectísima determinación de que a nadie le sea negada la facultad de seguir libremente la religión que ha escogido para su espíritu, sea la cristiana o cualquier otra que crea más conveniente, a fin de que la suprema divinidad, a cuya religión rendimos este libre homenaje, nos preste su acostumbrado favor y benevolencia. ${ }^{37}$

La concepción cristiana, hasta aquí, se dirige al hombre en cuanto tal, como creación e hijo de Dios. Esto no implica una confusión con el concepto jurídico de persona, vocabulario que, de hecho, no era utilizado para esta cuestión. No obstante, como veremos a continuación, este panorama cambia y la posición cristiana queda prontamente ligada al concepto bajo análisis.

\subsection{El Concilio de Nicea}

El edicto de Milán, si bien no adoptó la religión cristiana como aquella del Imperio, fue el producto de la simpatía de Constantino por dicha fe. En particular, él

37 Transcripción del Edicto de Milán que figura en Lactancio, De mortibus persecutorum, en Miguel Artola, Textos fundamentales para la Historia, Madrid, Alianza, 1968, pp. 21-22. 
había notado que esta creencia podía constituir un eje de homogeneización en el marco de un amplio Imperio que, en virtud de su extensión territorial y diversidad cultural, se encontraba cada vez más fraccionado, de dificil gobernabilidad y con riesgos bélicos e internos.

Comprender cómo el concepto de persona en el marco del derecho combina de manera muchas veces confusa una semántica que lo vincula con el ejercicio de roles según la exteriorización en las relaciones jurídicas y otra que plantea cierta inmanencia o la relevancia de una sustancia que reclama un trato específico, requiere recordar los sucesos del Concilio de Nicea.

Tras el edicto de Milán, los cristianos tuvieron el derecho de profesar su religión. No obstante, habia algunas disidencias internas que provocaban desencuentros entre algunos sectores. Constantino, que había visto en el cristianismo un factor de unidad y un respaldo, mostró su preocupación por dichos desacuerdos. En ese marco, convocó a un encuentro ecuménico que se celebró el año 325 en la ciudad de Nicea.

Entre el 20 de mayo y el 25 de julio funcionó el conocido como Concilio de Nicea. El principal punto que se trató allí -y el que nos interesa en este trabajo- fue la naturaleza de Cristo. ¿Tenía este naturaleza humana, divina o ambas? ¿Había sido creado por Dios o era parte de la esencia de Dios? ¿Tenía o no principio? ${ }^{38}$ El lenguaje utilizado para dirimir la cuestión fue el griego. El acuerdo al cual se llegó fue que este tiene una doble naturaleza: divina y humana. No obstante, es una sola persona que es indivisible y única. De esta manera, la idea de persona en Cristo permitía conjugar lo humano y lo divino sin dejar de distinguir entre ellos. La cuestión es que el término griego utilizado en varias ocasiones no fue $\pi$ ¡ó $\omega \pi \circ \mathrm{v}$,

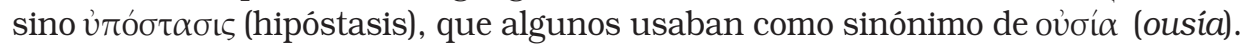
El término de hipóstasis, como sustrato, parecía resaltar mejor la condición de lo que se entendia por persona. ${ }^{39}$

Recuerda Herrera que, si en Dios se usara la palabra "persona" como sustancia (ousía), se llegaría a la conclusión de que en la Santísima Trinidad habría tres ousías o divinidades distintas en su ser sustancial. No obstante, ello contradice contundentemente el dogma de la Santísima Trinidad que postula tres Personas (hipóstasis): Padre, hijo y Espíritu Santo y un solo Dios. De la misma manera, en Cristo cada ousía subsiste en la misma hipóstasis (la persona divina del Verbo encarnado). En caso contrario, si cada naturaleza realizara en Cristo su propia hipóstasis, el resultado serían dos personas: una humana y otra divina. Entonces, no habria un solo Cristo, sino dos (uno humano y otro divino) unidos como dos sustancias en un mismo ser sustancial mixto. ${ }^{40}$

38 Alois Grillmeier, Cristo en la tradición cristiana: desde el tiempo apostólico hasta el Concilio de Calcedonia (451), Salamanca, Sigueme, 1997.

39 Ferrater Mora, "Persona”, op. cit., pp. 2759-2764.

40 Daniel Herrera, La persona y el fundamento de los derechos humanos, Buenos Aires, EdUCA, 2012, pp. 320-321. 


\subsection{San Agustín}

La Antigüedad tardía, en clave filosófica, se caracteriza por una impronta del pensamiento cristiano; en particular, por el movimiento conocido como la Patrística. Uno de los principales representantes fue Agustín de Hipona, filósofo sumamente influyente y que se convirtió al cristianismo por su contacto con San Ambrosio de Milán, quien le habria introducido al estudio de los escritos de Plotino y de San Pablo.

San Agustín (354-430), si bien es ampliamente conocido por su texto La ciudad de Dios ${ }^{41}$ y por las disputas que mantuvo con Pelagio, también dedicó parte de su obra a la concepción de la persona, sobre todo en pos de lograr que esta noción pudiera usarse sin confundir la Trinidad y el ser humano. No obstante ello, comenta Arias Reyero que en la obra de San Agustín aparecen al menos cinco sentidos para "persona":

Persona tiene en San Agustín cinco sentidos diferentes: 1) Ministerio, rol: hablar por propia persona o hablar en persona de otro; así en las teofanías: los ángeles obran ex persona Dei. 2) Sujeto que asume una función, título, dignidad, oficio. 3) Individuo concreto, hombre o mujer. 4) El Verbo encarnado tiene una sola persona. 5) El Padre, Hijo y Espíritu Santo son persona. ${ }^{42}$

En De Trinitate, el obispo de Hipona se preocupó más bien por las Personas divinas (que no pueden ser consideradas como simples sustancias) y, para ello, se remitió a la noción aristotélica de relación. ${ }^{43}$ De hecho, señala que el ser es un término absoluto mientras que la persona es un término relativo. ${ }^{44}$ No obstante, agregó algo más: la experiencia aquella que le va a la persona en su propia personalidad. Esto tiene un efecto no menor: la idea de persona deja de enfocarse en la relativa exterioridad para concentrarse en la intimidad. La idea de relación, en este marco, fue útil para destacar el ser relativo a sí mismo de cada Persona divina por lo que hay tres Personas y no solo una. La idea de intimidad, por su parte, le sirvió para hacer de esta relación consigo mismo, no una relación abstracta, sino concreta y real. ${ }^{45}$

\section{HECHOS POLÍTICOS DE RELEVANCIA QUE CIERRAN}

\section{LA ETAPA}

En el año 330, dado que el centro de gravedad del Imperio romano se había trasladado hacia el lado oriental, Constantino mudó la capital a Constantinopla, ciudad que él mismo había fundado sobre la antigua Bizancio.

\footnotetext{
41 San Agustín de Hipona, La Ciudad de Dios. Obras completas, FAEy BAC. Disponible en www.augustinus.it, fecha de consulta: 3 de mayo de 2019.

42 Maximino ArIas Reyero, "La doctrina trinitaria de San Agustín (en el De trinitate)", Teología y vida 30 (4) (1989), p. 265.

$43 \mathrm{Al}$ respecto, se puede consultar Aristóteles, Metafisica, V, 1013b-1025a

44 "Aliquid singulare atque individuum" (SAn Agustín. De Trinitate, VII, 6, 11).

45 Ferrater Mora, "Persona”, op. cit., pp. 2760-2761. 
Otro hecho que tuvo gran trascendencia en lo político ocurrió en el año 380, cuando el emperador Teodosio I, conocido como "el Grande", fuertemente influido por el obispo de Milán, San Ambrosio, declaró que el cristianismo sería la religión oficial del Estado.

En el año 395, tras la muerte de Teodosio I, el Imperio romano se dividió en dos: el Imperio romano de Oriente y el Imperio romano de Occidente. Este último cayó en el año 476 cuando los ostrogodos ocuparon la ciudad de Roma. Este hito se considera el fin de la Edad Antigua y el comienzo de la Edad Media -por supuesto que esta postura admite matices, sobre todo si se tiene en cuenta que la Tardoantigüedad es una etapa de transición que, para muchos, se extenderia hasta el siglo VIII-. La vastísima unidad política y territorial que ocupaba aquel lado imperial se disolvió de repente y comenzó el tiempo del feudalismo. Por su parte, el Imperio romano de Oriente subsistió casi mil años más, hasta 1453, cuando Constantinopla cayó en manos de los turcos.

\section{CONSIDERACIONES FINALES}

Para sintetizar esta primera etapa cabe recordar la antigua metáfora teatral que vincula al concepto jurídico de persona con una tecnología que le permite al actor hacerse oir, hacerse notar como personaje e interpretar un rol en el marco de una escena pautada. Las metáforas constituyen figuras retóricas que facilitan la cognición de un fenómeno nuevo al vincularlo con uno ya conocido. Por ello, revisten un carácter pedagógico ya que enseñan al enfatizar en algunos aspectos por sobre otros. De esta manera, el hecho de que la máscara sea el elemento conocido desde el cual se formatea el papel que juega un sujeto en el derecho resulta relevante. Desde alli es que es posible comenzar a interrogar acerca de si lo que cuenta en el campo jurídico es meramente la interpretación de un rol, es decir, ser destinatario y ejecutor de normas jurídicas, con prescindencia de la humanidad detrás de dichas normas, o si, por el contrario, los roles importan al derecho a partir de la necesidad de operativizar de la mejor manera al derecho. Así, por ejemplo, Viola menciona que los estatus han retornado, no de la misma manera en que existian en el derecho romano, pero sí para ser una herramienta de tutela de los sujetos de derecho, no ya como seres abstractos y universales, sino en sus relaciones concretas (por ejemplo, un consumidor frente a un proveedor, un hijo menor de edad en sus relaciones filiales, una mujer en su relación de pareja, un trabajador en su relación laboral con un empleador, etc). En tal sentido, la metáfora es útil para dilucidar qué expectativas existen sobre el campo jurídico. A pesar de ello, esta breve introducción es insuficiente puesto que se ha centrado en la Antigüedad y la historia del concepto es sumamente amplia. Durante la Edad Media aparecerán nuevas concepciones que, además de la ligazón con la divinidad, resaltarán el factor racional de la persona. La Modernidad llevará al extremo dicha racionalidad, pero también se preguntará por el vínculo entre el individuo y la comunidad política. Es en esta etapa donde la idea del sujeto de derechos como 328 un ser abstracto y universal toma lugar. A pesar de los esfuerzos por consagrar los derechos humanos en diferentes documentos jurídicos, las insuficiencias en las concreciones seguian siendo insuficientes. Por ello, han reaparecido los roles de 
manera tal que el sujeto sea activamente protegido. Desde allí es que Viola llega a la conclusión antedicha sobre el retorno de los estatus.

Para volver a concentrar la atención en esta primera etapa cabe destacar, no solo la metáfora, sino también las características objetivas que tiene la idea de ser humano como parte de la naturaleza y que, por ser tal, debe adaptarse al equilibrio cósmico. El derecho trata del establecimiento de un orden que, en caso de ser dañado, debe ser restaurado. El cristianismo marcó un punto de inflexión en la historia política al considerar a los hombres como iguales en cuanto hijos de Dios, con independencia de su estatus social. Por otro lado, remarca el vínculo directo entre la deidad y los sujetos a la par que deja en un plano independiente al Estado. Ahora bien, respecto a la historia del concepto de persona, si existe un hecho de suma relevancia en relación con el cristianismo, este es sin duda el Concilio de Nicea, en el que los intentos por dilucidar la naturaleza y la personería de Cristo se tradujeron en el uso del término "persona", no ya con el sentido jurídico o teatral de interpretar roles, sino con la idea de una sustancia. Es esta visión la que será la base para las posteriores reflexiones sobre el ser humano como trasfondo ontológico sólido del concepto jurídico de persona que exige un trato con ciertas características.

\section{BIBLIOGRAFÍA}

Álvarez Gardiol, Ariel, Manual de Filosofia del Derecho, Buenos Aires, Astrea, 1979.

Argüello, Luis Rodolfo, Manual de derecho romano. Historia e instituciones, Buenos Aires, Astrea.

Arias Reyero, Maximino, "La doctrina trinitaria de San Agustín (en el De trinitate)", Teología y vida 30 (4) (1989), pp. 249-270, en https://repositorio.uc.cl/bitstream/handle/11534/15188/000413411.pdf?sequence=1

BAUlaudÉ, Jean-François, "Instituir el bien. La problemática filosófica de la justicia en la Antigüedad (Platón, Aristóteles, Epicuro)”, en Patrick Wotling (dir,), La justicia, Buenos Aires, Nueva Visión, trad. Viviana Ackerman, 2008.

Belmonte, Miguel Ángel, "Los antecedentes remotos: тœó $\omega \omega \pi$ rov en la literatura griega”, Espíritu LIX (139) (2010), pp. 195-205, en https://dialnet.unirioja. es/descarga/articulo/4099088.pdf

Betancourt, Fernando, Derecho romano clásico, 3 ed., Sevilla, Universidad de Sevilla, 2007.

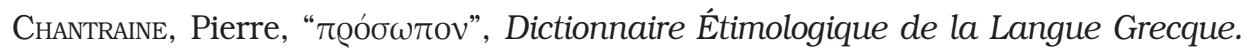
Histoire des mots, t. III ( $\Lambda$-П), Paris, Klincksieck, 1974.

CoRominas, Joan, "Persona”, Diccionario Crítico Etimológico Castellano e hispánico, ME-RE, con la colaboración de José A. Pascual, Madrid, Gredos, 1981.

Di Pietro, Alfredo y Lapieza Eldi, Ángel Enrique, Manual de derecho romano, 4ํe. ed. Buenos Aires, Ediciones Buenos Aires, 1985. 
Du PAsguier, Claude, Introducción a la teoría general del derecho y la filosofia jurídica, Lima, Libreria e imprenta Gil, 1944.

Epicteti, Dissertationes ab Arriano digestae. Epictetus. Heinrich Schenkl (ed.), Leipzig, B. G. Teubner, 1916 (publicado por Perseus Project).

Epictetus, The Works of Epictetus: His Discourses, in Four Books, the Enchiridion, and Fragments, New York, Thomas Nelson and Sons, trad. Thomas Wentworth Higginson, 1890.

ERnout, Alfred y MeIllet, Antoine, Dictionnaire étymologique de la langue latine. Histoire des mots, correcciones de Jacques André, 4ํe., Paris, Klincksieck, 2001.

Fassò, Guido, Historia de la Filosofia del Derecho, t. I, trad. José Lorca Navarrete, Madrid, Pirámide, trad. José Lorca Navarrete.

Ferrater Mora, José, "Persona", Diccionario de filosofia, t. III, K-P, edición actualizada bajo la dirección de Josep-Maria Terricabras, Barcelona, Ariel, 1994, pp. 2759-2764.

Grillmeier, Alois, Cristo en la tradición cristiana: desde el tiempo apostólico hasta el Concilio de Calcedonia (451), Salamanca, Sígueme, 1997.

Gutiérrez-Alviz y Armarlo, Faustino, "Persona”, Diccionario de Derecho Romano, $3^{\text {o }}$ ed., Madrid, Reus, 1982.

Hause, Steven y Maltby William, Western Civilization: a history of European Society from Antiquity to Renaissance, West/Wadsworth, 1998.

HERrera, Daniel, La persona y el fundamento de los derechos humanos, Buenos Aires, EdUCA, 2012.

KYLE, Donald, Sport and Spectacle in the Ancient World, New Jersey, John Wiley and Sons, 2014.

Lactancio, De mortibus persecutorum, en Miguel Artola, Textos fundamentales para la Historia, Madrid, Alianza, 1968.

Larmour, David H. J., The Arena of Satire: Jouvenal's Search for Rome, Norman, University of Oklahoma Press, 2016.

LELL, Helga, "Instituciones jurídicas y filosóficas en la Edad Media”, en Lidia Raquel Miranda (ed.), La Edad Media en capítulos. Panorama introductorio a los Estudios Medievales, Santa Rosa, EdUNLPam, 2014, pp. 85-112.

LÉTOUBLon, François, "La personne et ses masques: remarques sur le développement de la notion de personne et sur son étymologie dans l'histoire de la langue grécque”, Faits de langues 3 (1994), pp. 7-14, en https://www.persee.fr/ doc/flang_1244-5460_1994_num_2_3_900 Stuart Jones con la colaboración de Roderick McKenzie, Oxford, Clarendon Press, 1940 (publicado por Perseus Project). 
LidDEll, Henry George y Robert ScotT, An Intermediate Greek-English Lexicon, Oxford, Clarendon Press, 1889 (publicado por Perseus Project).

Miranda, Lidia Raquel y Helga María Lell, "Derecho divino y derecho positivo en la Epístola a Filemón: una mirada a las esferas de la esclavitud y la hermandad desde la filosofia jurídica existencia”, en María Cecilia Colombani (coord.), Actas de las Segundas Jornadas de Filosofia Antigua Doctor Francisco Olivieri, Mar del Plata, UNMDP, 2012.

Miranda, Raquel y Helga Lell, "Coexistencia de instituciones de órdenes normativos contrapuestos en la Epístola a Filemón”, Revista Classica 26 (1) (2013), pp. 117-129, en https://ri.conicet.gov.ar/handle/11336/26894

Morales, José Ignacio, Derecho Romano, 3ed., México, Trillas, 1989.

NÉNDONCElLE, Maurice, "Prósopon et persona dans l'antiquité classique. Essai de bilan lingüistique”, Revue des Sciences Religieuses 22 (3-4) (1948), pp. 277-299.

PARICIO, Javier, "Persona: un retorno a los orígenes", en Matilde Cuena Casas, Luis Antonio Anguita Villanueva y Jorge Ortega Doménech (coords.), Estudios de derecho civil en Homenaje al profesor Joaquín José Rams Albesa, Madrid, Dykinson, 2015.

PetrT, Eugène, Tratado elemental de Derecho Romano, 23ํe., México, Porrúa, trad. de la novena edición francesa y aumentado por José Ferrández González, 2015.

Polybus, Historiae, Theodorus Büttner-Wobst after L. Dindorf, Leipzig, Teubner, 1893 (publicada on-line por Perseus Project).

Ribas Alba, José María, Persona: desde el derecho romano a la teología cristiana, 2 ed., Granada, Comares, 2012.

San Agustín de Hipona, La Ciudad de Dios. Obras completas, FAE y BAC, en www.augustinus.it, fecha de consulta: 3 de mayo de 2019.

Schlossmann, Siegmund, Persona und Prósopon im Recht und im christlichen Dogma, Darmstadt, Wissenschaftliche Buchgesellschaft, 1968.

Smiтh, Christopher, The Etruscans. A very short introduction, Oxford, Oxford University Press, 2014.

Sófocles, Antígona, Madrid, Gredos, trad. Asella Alamillo Sánz, 2014.

Sófocles, Edipo Rey, Madrid, Gredos, trad. María Rosa Lida, 2014.

Sophocles, Oedipus the king. Oedipus at Colonus. Antigone, vol. 1, London, New York, William Heinemann; The Macmillan Company, trad. F. Storr, 1912 (publicada por Perseus Project on line).

SteIngräBer, Sthephan, Abundance of life. Estruscan Wall painting, Los Ángeles, Getty Publications, 2006.

Stoddart, Simon K. F., "Phersu", Historical Dictionary of the Etruscans, New York,

Scarecrow Press, 2009. 
Helga María Lell

Viola, Francesco, "El estatuto jurídico de la persona", Derecho y cambio social 40 (XII) (2015), en https://www.academia.edu/11793156/El_estatuto_ jur\%C3\%ADdico_de_la_persona

Zorraguín Becú, Ricardo, Historia del Derecho argentino, t. I, Buenos Aires, Perrot, 1966. 